\title{
Integration of the SMS to IMS in Estonian Seveso II establishments: selected case studies
}

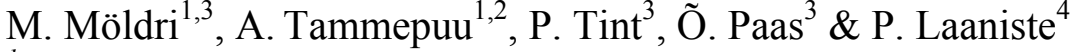 \\ ${ }^{1}$ Estonian Academy of Security Sciences, Estonia \\ ${ }^{2}$ Estonian University of Life Sciences, Estonia \\ ${ }^{3}$ Tallinn University of Technology, Estonia \\ ${ }^{4}$ Estonian Ministry of the Interior, Estonia
}

\begin{abstract}
This paper concerns the integration of Safety Management Systems of the Estonian Seveso II establishments into ISO-based Integrated Management Systems (IMS). Estonia has an obligation to follow the requirements of the EU Seveso II Directive since joining the EU in 2004. Today altogether 51 enterprises with major accident hazards are in the official register. According to the data available at the Estonian Association for Quality, seventeen of these establishments have certified quality (ISO 9001), environmental (ISO 14001) management integrated systems. Therefore it is useful and politically sound to integrate the SMS to the IMS. The essential goal of the current study is to explain the application of the unified management system and to find characteristic features for further recommendations. The results have demonstrated that, in spite of different approaches, a number of common factors exist, enabling general recommendations to be worked out.
\end{abstract}

Keywords: emergency preparedness, safety management systems, major chemical hazard.

\section{Introduction}

The existence of mankind has been filled with disastrous events: both natural and anthropogenic. Major accidents and hazards are destabilizing factors for continuous and sustainable development [1]. During the last decades there has been a significant increase in the number of technological and natural disasters in Europe and worldwide [2]. Therefore it is very important to work out different 
kinds of measures and requirements for keeping the hazards and risks under control and avoiding emergencies. Today the requirements concerning safety management are available in international and national legal documents and also in a variety of international standards. Different requirements cover single organisations and also broader social structures on regional, national and international levels.

Industrial installations using dangerous chemicals in quantities, which can cause major accidents, have been under heightened attention in Europe for about thirty years. Nowadays the Seveso II Directive [3] sets out basic principles and requirements for safety policies and management systems, suitable for the prevention, control and mitigation of major accident hazards. This document belongs to the most remarkable EU Directives, supporting the protection of people and the environment from major accidental hazards [4]. The Seveso II Directive also includes the settings for Safety Management Systems for ensuring the systematic measures and control mechanisms in the establishments with a major accident hazard. Safety management systems are obligatory for establishments with a major accident hazard as failures of the management system often cause accidents.

Since the 1990s the International Standard Organization (ISO) has worked out standards for different management fields in organisations, based on the universal management cycle of plan-do-check-act (PDCA). Today several organisations over the world have implemented and certified integrated management systems (IMS), based on corresponding ISO standards and containing quality (ISO 9001) [5], environment (ISO 14001) [6] and often also occupational health and safety (OHSAS 18001) [7]. The latter is not based on ISO standards, but on a document of the British Standard Institute, which has generically adopted the structure of ISO 14001 and has been recognized in many countries. The ISO 14001 and OHSAS 18001 both contain requirements concerning emergency and safety management. Although the management systems, based on ISO standards, are structured differently from the SMS presented in the Appendix III of the Seveso II Directive, there are noticeable similarities between these systems, providing a basis to an integrated approach.

Until now many studies involve both: the safety management systems and the ISO standardized and certified management systems but, simultaneously only a few studies have been carried out about the integration of these two categories. The situation is discussed more thoroughly in the next section of the paper.

Taking into account what was discussed so far, the essential goal of the current study is to explain the application of the unified management system and to find characteristic features for further recommendations. The particular aims and closer research interests concern the following issues: management policies; counteractions between ISO-based management systems and the SMS during the integrated development; the application of risk assessment and emergency planning in the SMS-containing IMS; the applicability and compatibility of such components of the IMS as operational control, management of change, monitoring performance and also audit and review to fulfil the corresponding requirements of the SMS. 
The work discussed was carried out within the frames of a research workgroup on risk management and civil protection of the Estonian Academy of Security Sciences.

\section{Integration of SMS to IMS}

\subsection{Safety Management System}

The Seveso II Directive requires the compilation of a "Major Accident Prevention Policy" (MAPP) and "Safety Management System" (SMS) from all establishments with a major accident hazard $[3,8]$ on the basis of a summarized qualifying quantity by Annex I of the Directive. In accordance with Annex III of the Directive the SMS must embrace the following issues [3,9]:

1. Organisation and personnel

2. Identification and evaluation of major hazards

3. Operational control

4. Management of change

5. Planning for emergencies

6. Monitoring performance

7. Audit and review

The Safety Management System can be briefly defined as the system for implementing safety management [10]. SMS substantially means multiple activities, initiatives, programs, etc., consolidated by organisational, human and technical aspects [11]. SMS in a formal sense is a framework, holding a large package of documents, containing different procedures, manuals, charts, reports, records, emergency plans, etc. [12]. The safety management system is considered to be a basic component of the organisations' safety culture $[13,14]$. The size and orientation of SMS procedures are deeply dependent on identification and evaluation of major accident hazards and selection of risk analysis method(s) [15]. The integration of the principles of inherent safety and land use planning into the plant safety management system permits the reduction of possible consequences [16]. The SMS of neighbouring Seveso establishments may be organized in clusters, which enables observing common risks and possible counteractions as well as knowledge exchange and coordinated planning of proactive and re-active measures [17].

\subsection{Integration}

The integration of legally required and standardised management systems is possible and recommendable due to the fact that they have several analogous or similar system components, although structured in different ways. In principle the activities for the prevention of accidents and the mitigation of consequences generically follow the PDCA management scheme, on which the ISO standards are based [12]. It is important to implement the SMS in consistence with a broader management system, like an integrated health, safety and environment 
(HSE) management system, total quality management (TQM) system, etc. which, already exist and cover the entire management of a particular organisation [10].

Slovenian researchers conducted a study, where they, among other things, also observed the integration of SMS and IMS [18]. They brought out that 22 (71\%) of their selected 31 establishments with a major chemical accident hazard had introduced the SMS as being related or completely integrated within ISO/OHSAS management system(s).

\section{SMS in IMS of Estonian enterprises}

According to the data of the Estonian Rescue Board [19] there are 51 establishments with a major chemical accident hazard in Estonia (further also Seveso II establishments). Among these, 19 organisations (37\%) have implemented and been certified by ISO management standards, whereby 17 (33\%, that makes about $1 / 3$ of the total) have an integrated approach, based at least on two standards [20]. More precisely: 12 Seveso II establishments have integrated quality (ISO 9001) and environmental (ISO 14001) management systems, 4 have, in addition to the two mentioned, an occupational health and safety management system (OHSAS 18001), in addition 1 also has Environmental Management and Audit Scheme (EMAS) registration.

Table 1: $\quad$ Contingent correspondence between SMS and ISO 14001.

\begin{tabular}{|l|cl|}
\hline $\begin{array}{l}\text { Safety Management System } \\
\text { (SMS) }\end{array}$ & & ISO 14001 \\
\hline Organisation and personnel & 4.2 & Environmental policy \\
& 4.3 .2 & Legal and other requirements \\
& 4.3 .3 & Objectives, targets and programme(s) \\
& 4.4 .1 & Resources, roles, responsibility and \\
& 4.4 .2 & authority \\
& 4.4 .3 & Competence, training and awareness \\
\hline Identification and evaluation & 4.3 .1 & Environmental aspects \\
of major hazards & & \\
\hline Operational control & 4.4 .4 & Documentation \\
& 4.4 .5 & Control of documents \\
\hline Management of change & 4.4 .6 & Operational control \\
\hline Planning for emergencies & 4.3 .3 & Objectives, targets and programme(s) \\
\hline Monitoring performance & 4.4 .7 & Emergency preparedness and response \\
& 4.5 .1 & Monitoring and measurement \\
& 4.5 .2 & Evaluation of compliance \\
& 4.5 .3 & Nonconformity, corrective action and \\
& & preventive action \\
\hline Audit and review & 4.5 .5 & Internal audit \\
& 4.6 & Management review \\
\hline
\end{tabular}


Recently we carried out a study, concerning the implementation of SMS in Estonian Seveso II establishments. During the study we turned our attention to the connections between safety management systems and the ISO 9001, ISO 14001 and OHSAS 18001. Other directions of the study were the evaluation and audit of companies safety management systems in Estonian conditions, but these are not under observation in the current paper.

One important outcome of the study was the guidance, where the previously mentioned connections were brought in as correspondence between the 7 main components of SMS and the subdivisions of ISO 9001, ISO 14001 and OHSAS 18001. The excerpt of that work, demonstrating the proposed correspondences of SMS with ISO 14001 is presented in Table 1.

The guidance was made publicly available and has been introduced and recommended to many Estonian Seveso II establishments for practical application purposes.

\section{Selected case studies}

\subsection{General}

Today, as previously stated, about $1 / 3$ of Seveso II establishments in Estonia have implemented the integrated management system. We selected for our case studies three of these, belonging to different economic activities. One aim of the selection was finding organisations, which were not competitors with each other. This allowed for good prerequisites for possible further cooperation between the specialists of the organisations in the field of IMS and SMS development.

The common characteristics of the organisations were the following: firstly, all three belonged to international corporations and secondly, all the establishments had implemented and certified at least the ISO 9001 and ISO 14001 as IMS and thirdly, all three have the additional duty to follow the internal standards of their international corporations. One of the three case study establishments belongs to the upper tier and the two others to the lower tier, according to the quantity of dangerous substances by thresholds, brought out in Annex I of the Seveso II Directive [3, 21].

Our study is derived from the previously described guidance, where the connections between the SMS and ISO management standards are brought forth. The document analysis was carried out, concerning: safety reports or descriptions of SMS-s, handbooks of IMS-s, procedures and guides of IMS-s and also emergency plans. During the case studies relatively more attention was paid to the SMS-specific components: identification and evaluation of major hazards (risk assessments) and planning for emergencies.

\subsection{Establishment A: a process industry}

This establishment is a plant, producing chemical products. The major accident hazard originates mostly from the use of extremely flammable gases in the 
processes. The establishment belongs to the lower tier by Annex I of Seveso II Directive.

The SMS was implemented on the basis of and integrated to the already existing ISO 9001 quality management system (QMS). As a matter of fact the first step of implementing SMS and integrating it to QMS was the compilation of the procedure for emergency preparedness, through which the obligatory components of the SMS were integrated. Later, when the environmental management system (EMS) on the basis of ISO 14001 was implemented, the emergency management part of it was already adopted from the SMS subdivision of the initially integrated system of quality and safety management. Today the formal part of the management system is generically Intranet-based. It is divided into functional modules and the SMS components belong mostly to the module of environmental and occupational health and safety management.

The establishment had no need to compile special safety politics or MAPP, as safety was natural component of the management politics of the international company, which the establishment belonged to. The handbook of quality (actually the handbook of IMS) serves as a central guidance document, which embraces also the key elements and links to the SMS-specific documents. The organisational structure scheme and responsibilities of the personnel, initially defined by QMS, were revised and amended during the implementation of SMS and EMS.

Identification and evaluation of major hazards and planning for emergencies are both regulated by the emergency preparedness procedure of the IMS, which has references to the procedures of environmental aspects assessment and the assessment of occupational hazards and risks. Additionally, the internal standards of the corporation are considered. The identification of hazards is carried out by the well-known HAZOP $[22,23]$ methodology in combination with the risk matrix for the assessment of risks. The risk matrix used is rather ordinary: $5 * 5$ - with five-point scales for both, likelihood and consequences. The risk assessment outcome documents are in the status of appendixes of the IMS emergency preparedness procedure. The environmental aspects and occupational risks are assessed separately, but the principles are quite similar to major hazard risk assessment. The Emergency plan of the establishment with its guides is also formally standing as the appendix of the same IMS procedure. So the specific requirements, emanating from Seveso II Directive and Estonian Chemicals Act [24], are completely integrated to the IMS of that establishment.

The required elements of SMS such as operational control, management of change, monitoring performance, audit and review were covered by ISO 9001 based QMS procedures and were taken over during the implementation of the SMS and ISO 14001 based EMS. The management documentation was amended only with some new procedures and guides, concerning mainly the hazardous parts of the technological processes.

\subsection{Establishment B: an oil terminal}

The main activity of this establishment is the handling of oil products at a port terminal being one of the largest of its kind in Estonia. The establishment 
belongs to the upper tier by Annex I of the Seveso II Directive. The corporation, to which the establishment belongs, has several terminals in Estonia and abroad.

The company implemented an integrated quality, environmental and safety management system from the very beginning applying the standards ISO 9001 and ISO 14001 and so the SMS documents were adapted to the IMS framework since their compilation. The central guidance document is the handbook of the management system, which gives directions to all components of the system. The handbook presents, among other things, the structural scheme of the personnel and the special duties of the personnel concerning safety are precisely set forth in job descriptions

The establishment has a uniform management policy, including the essential elements of MAPP. There is no special procedure of emergency preparedness in the framework of IMS. Instead of this, the essential elements of SMS such as safety report, risk assessment and emergency plan are integrated into IMS to cover the provisions of the subdivision 4.4.7 "Emergency preparedness and response" of the ISO 14001. Until today the risk identification of major hazards was carried out primarily by deterministic approach, relying on the competent opinions of specialists, experts and consultants. The risks were assessed by a $5 * 5$ risk matrix. The establishment is planning the application of HAZOP to improve the identification of hazards.

Operational control, management of change, monitoring performance, audit and review were conceived from the outset of the implementation of ISO-based IMS to cover also the safety management issues, taking into consideration the specific requirements for SMS as obliged by the Seveso II Directive.

\subsection{Establishment C: a water treatment plant}

The establishment specialises in water treatment. The dangerous chemical chlorine - is only used in one of the many sites, where the company operates: the water treatment plant. Therefore the IMS, covering the entire company, and the SMS, being required only in one certain site, were developed quite separately until recently. The water treatment plant is a lower tier establishment.

The company at first implemented and certified the ISO 9001 and ISO 14001 management systems and so the application of the SMS in water treatment had taken place already within the conditions of the existing IMS. The IMS of quality and environmental management involved the procedure of crisis management, covering the provisions of 4.4.7 "Emergency preparedness and response" of the ISO 14001. The procedure was designed to organise preparedness against different types of possible emergencies beyond the whole company and one of the guides, emanating from the procedure was addressed to a chlorine accident.

Simultaneously, to better respond to the SMS requirements, special documents such as a chlorine accident risk assessment and emergency plan were compiled for the water treatment plant with the help of a consultation company. The risks were assessed by a $5 * 5$ risk matrix. Today the emergency plan is integrated with the crisis management procedure and the guide for chlorine accidents. 
Later, during the implementation of OHSAS 18001 and its integration into the IMS the whole subject of risk was thoroughly revised and a special procedure of risk management was compiled. The procedure is designed to enable a uniform approach to different types of risks as well as environmental aspects. In relation to the former the company actuated the HAZOP methodology, covering all the production units, including the water treatment. The future orientation, concerning major accident risk from chlorine, is the revision of the possible major accident scenarios on the basis of HAZOP and drawing the risk assessment step-by-step together with the methodological process, derived from the risk management procedure of the IMS. Today there are good outlooks for this as the outputs of generic (of the whole company) and the chlorine emergency specific risk assessment result on $5 * 5$ risk matrixes, although the scales, levels and other criteria are currently diversely defined.

The company had no need to develop special solutions for SMS components such as operational control, management of change, monitoring performance, as well as, audit and review since the corresponding measures of the standardsbased IMS enabled complete coverage of these requirements.

\section{Conclusion}

The results of the case studies confirmed the expectations about the mutual impacts of the ISO-based IMS and SMS, enabling their integration into a unified management system. The case study establishments had composed unified policies in the framework of IMS, which contained the essential elements of quality, environmental and safety management and therefore there was no need for the compilation of a special MAPP.

The identification and evaluation of major hazards in the case study organisations was conducted by risk assessment, as is required by the Estonian Chemicals Act [24]. The major chemical accident risk assessment process was integrated to the IMS, although to a different degree, depending on the particular establishment. The three case study establishments received orientation to introduce the HAZOP methodology, which serves a broader target than only major chemical hazard identification, enabling systematic support for the improvement of the whole risk management in the frames of IMS. The default selection in the three establishments for risk assessment outputs was the risk matrix method, being simultaneously used also for other risk types and aspects. In spite of the multiple drawbacks of the risk matrix technique [25, 26], we still suggest the use of it for establishments, where a quantitative risk assessment approach is not the default selection, as it enables the comparison of major accident risks with other risk types in the organisation - either directly, if the defined scales and criteria are universal enough, or with the help of additional assessment tools for comparison and converting, specially worked out for that purpose.

The emergency planning principles were decreed and described in the corresponding IMS procedures. The emergency plans, designed for major accidents, were integrated to the IMS frameworks of the organisations. 
The IMS based on ISO/OHSAS permitted the direct execution of the requirements of the SMS, involving operational control, management of change, monitoring performance as well as on audit and review.

Finally we recommend, on the strength of the current study experience, more cooperation and information exchange between the Seveso II establishments in the field of safety management and its integration to the ISO/OHSAS based management system.

\section{Acknowledgements}

European Social Fund's Doctoral Studies and Internationalisation Programme DoRa supported this research. The authors would like to thank the organisations, which agreed to participate in the case studies and also Tia Ruutopõld for linguistic advice and correction.

\section{References}

[1] EC. Assessing the Potential for a Comprehensive Community Strategy for the prevention of Natural and Manmade Disasters, Final Report, March 2008. http://ec.europa.eu/echo/civil_protection/civil/pdfdocs/stakeholders/ potential_prevention strategy.pdf

[2] Carpignano, A., Golia E., Di Mauro, C., Bouchon, S., and Nordvik, J-P., A methodological approach for the definition of multi-risk maps at regional level: first application. Journal of Risk Research 12(3-4), pp. 513-534, 2009.

[3] EC. Council directive 96/82/EC of 9 December 1996 on the control of major-accident hazards involving dangerous substances, OJ No L 10 of 14 January 1997 (Seveso II-Directive), and Directive 2003/105/EC of the European Parliament and of the Council of 16 December 2003 amending Council directive 96/82/EC, OJ of 31 December 2003.

[4] Salvi, O. and Gaston, D., Risk assessment and risk decision-making process related to hazardous installation in France. Journal of Risk Research, 7(6), pp. 599-608. 2004.

[5] ISO 9001:2008 Quality management systems. Requirements with guidance for use.

[6] ISO 14001:2004 Environmental management systems. Requirements with guidance for use.

[7] BS OHSAS 18001:2007 Occupational health and safety management systems. Requirements.

[8] Duijm, N.J. and Goossens, L., Quantifying the influence of safety management on the reliability of safety barriers. Journal of Hazardous Materials, 130, pp. 284-292, 2006.

[9] Basso, B., Carpegna, C., Dibitonto, C., Gaido, G., Robotto, A. and Zonato, C., Reviewing the safety management system by incident investigation and performance indicators. Journal of Loss Prevention in the Process Industries, 17, pp. 225-231, 2004. 
[10] Mitchison, N. and Papadakis, G.A., Safety management systems under Seveso II: Implementation and assessment. Journal of Loss Prevention in the Process Industries, 12, pp. 43-51, 1999.

[11] Harms-Ringdahl, L., Relationships between accident investigations, risk analysis, and safety management. Journal of Hazardous Materials, 111, pp. 13-19, 2004.

[12] Bragatto, P.A., Agnello, P., Ansaldi, S.M. and Pittiglio, P., The digital representation of safety systems at "Seveso" plants and its potential for improving risk management. Journal of Loss Prevention in the Process Industries, 23, pp. 601-612, 2010.

[13] Fernandez-Muniz, B., Montes-Peon, J.M. and Vazquez-Ordas, C.J., Safety management system: Development and validation of a multidimensional scale. Journal of Loss Prevention in the Process Industries, 20, pp. 52-68, 2007.

[14] Sales, J., Mushtaq, F., Christou, M.D. and Nomen, R. Studt of Major Accidents Involving Chemical Reactive Substences: Analysis and Lessons Learned. Process Safety and Environmental Protection, 85(2), pp.117-124, 2007.

[15] Demichela, M., Piccini, N. and Romano, A. Risk analysis as a basis for safety management system. Journal of Loss Prevention in the Process Industries, 17, pp. 179-185, 2004.

[16] Vierendeels, G., Reniers, G.L.L. and Ale, B.J.M., Modeling the major accident prevention legislation change process within Europe. Safety Science, 49, pp. 513-521, 2011.

[17] Reniers, G.L.L., Ale, B.J.M., Dullaert, W. and Soudan K., Designing continuous safety improvement within chemical industrial areas. Safety Science, 47, pp. 578-590, 2009.

[18] Gerbec, M. and Kontic, B. Implementation of the Seveso II Directive in Slovenia: Survey of implementation and opinions of operators regarding its safety benefits. Safety Science, 47, pp. 561-568, 2009.

[19] Suurõnnetuse ohuga ettevõtete nimekiri, Päästeamet [The list of establishments with major accident hazard, Estonian Rescue Board], www.rescue.ee/kemikaaliohutus/ohtlikudettevotted

[20] Sertifikaatide andmebaas, Eesti Kvaliteediühing [Database of certificates, Estonian Association for Quality], http://www.eaq.ee/sisu/sertifikaatideandmebaas

[21] European Commission, Chemical Accidents (Seveso II) - Legislation, http://ec.europa.eu/environment/seveso/legislation.htm

[22] BS IEC 61882:2001 Hazard and operability studies (HAZOP studies) Application guide.

[23] EN 31010:2010 Risk management - Risk assessment techniques.

[24] Parliament of Estonia. Chemicals Act. State Gazette I, 47, 697, 1998.

[25] Levine, E. S., Improving risk matrices: the advantages of logarithmically scaled axes. Journal of Risk Research, 15(2), pp. 209-222, 2011.

[26] Cox, L.A. Jr., What's Wrong with Risk Matrices? Risk Analysis, 28(2), pp. 497-512, 2008. 